\title{
CONDIÇÕES E POSSIBILIDADES DE PROTEÇÃO DOS CONHECIMENTOS TRADICIONAIS NA AMAZÔNIA
}

\author{
Luanna Tomaz de Souza ${ }^{1}$ \\ Vanderlei Portes de Oliveira ${ }^{2}$
}

\section{RESUMO}

$\mathrm{O}$ artigo analisa em que medida os conhecimentos tradicionais associados à biodiversidade encontram proteção no sistema clássico de propriedade intelectual. Em um método dedutivo de análise, realiza-se uma revisão bibliográfica no Direito e nas Ciências Sociais para análise crítica do sistema clássico de propriedade intelectual. Também é realizada uma pesquisa documental nas normais locais e internacionais que tratam da propriedade intelectual e da proteção dos conhecimentos tradicionais. Pode-se perceber as deficiências desses sistemas jurídicos, ainda pautados em formas individuais de proteção. É necessário discutir novas formas de amparo desses conhecimentos, a partir do reconhecimento dos conhecimentos emergentes.

PALAVRAS-CHAVE: propriedade intelectual; conhecimentos tradicionais; direito industrial; sociologia das emergências; Amazônia.

\section{CONDITIONS AND POSSIBILITIES OF PROTECTION OF TRADITIONAL KNOWLEDGE IN THE AMAZON}

\begin{abstract}
The article analyzes the extent to which traditional knowledge associated with biodiversity finds protection in the classic intellectual property system. In a deductive method of analysis, a bibliographic review is done in the Law and in the Social Sciences. Documentary research is also conducted in local and international standards dealing with intellectual property and the protection of traditional knowledge. One can see the deficiencies of these legal systems, still based on individual forms of protection. It is necessary to discuss new forms of protection of this knowledge, based on the recognition of emerging knowledge.
\end{abstract}

KEYWORDS: intellectual property; traditional knowledge; industrial law; Sociology of emergencies; Amazon

\section{INTRODUÇÃO}

A questão da biotecnologia, a saber, o debate acerca da conjugação do saber científico com o saber tradicional, seja como complementares, seja como antagônicos, é um

\footnotetext{
${ }^{1}$ Professora Doutora da Universidade Federal do Pará (Belém-Pará- Brasil) E-mail: luannatomaz@ufpa.br

2 Professor Doutorando da Universidade Federal Rural do Pará (Capanema-Pará- Brasil) E-mail: portes@ufra.edu.br
} 
campo propício para refletir acerca do que chamamos de novos paradigmas epistemológicos. Vale dizer, o conhecimento científico tal como o reconhecemos precisa ser revisto. A forma como a ciência moderna é caracterizada já não mais reflete as práticas cientificas que atualmente se adotam.

Isso nos leva a atuar em dois sentidos: um deles, de rever como a própria ciência se vê; outro, de rever a relação da ciência com as outras formas de conhecimento, especialmente o que chamamos de conhecimento tradicional.

Essa nova forma de ver o conhecimento científico e a tecnologia, terá diversas e importantes repercussões. Uma delas terá a nossa especial atenção, que é a mudança do paradigma da tutela da propriedade intelectual, que passará de um modelo que privilegia o labor individual, competitivo, com busca principalmente do lucro, para - ao menos em pontos sensíveis deste paradigma, como o é o do tratamento dos recursos genéticos - um conhecimento coletivo, difuso, colaborativo e em que o lucro é um simples efeito colateral.

Pergunta-se, desta forma: em que medida os conhecimentos tradicionais associados à biodiversidade encontram proteção no sistema clássico de propriedade intelectual. Para responder essa pergunta, foi realizada uma revisão bibliográfica em autores do Direito e das Ciências Sociais que analisam de forma crítica o sistema clássico de propriedade intelectual. Este sistema foi construído a partir de uma premissa centrada nas criações individuais e tem dificuldade de atender questões complexas, vividas no contexto amazônico, como a produção dos conhecimentos tradicionais. Além disso, também realizouse pesquisa documental nas normais locais e internacionais que tratam da propriedade intelectual e da proteção dos conhecimentos tradicionais.

\section{CONTEXTUALIZANDO OS CONHECIMENTOS TRADICIONAIS NA AMAZÔNIA}

A Região Amazônica estende-se mais de 5 milhões de $\mathrm{km}^{2}$ alcançando nove países sendo que o Brasil ocupa a maior parte. Dentro do contexto amazônico o conceito de população tradicional ganha ricos contornos diante da diversidade de tipos de solos, fauna, flora, etnias e culturas e contrapõe-se a uma visão histórica da floresta como um vazio demográfico a ser habitado, sem considerar suas populações residentes (caboclos, 
seringueiros, ribeirinhos, pescadores, índios, quilombolas, camponeses) (CAÑETE e CAÑETE, 2010).

Se formos contabilizar somente a população indígena, o censo brasileiro de 2010 identificou no país cerca de 896,9 mil de 305 etnias, das quais a maior é a Tikuna, e cerca de 274 línguas $^{3}$.

Essa abundância e diversidade que marcam o meio ambiente, assim como o cenário social da Amazônia, demandam um olhar mais próximo capaz de traduzir as especificidades encontradas. O conceito de população tradicional pode assim sem relativizado dentro do contexto Amazônico, visto que as populações amazônicas, até mesmo algumas que habitam um contexto urbano, podem ser consideradas como populações tradicionais. Além disso, há comunidades que podem ser identificadas como tradicionais externamente, mas que não se identificam como tais o que pode fragilizar o acesso a seus direitos (CAÑETE e CAÑETE, 2010). Para Arruda (1999, p. 79), ao refletir sobre o conceito, as populações tradicionais se diferem porque:

apresentam um modelo de ocupação do espaço e uso dos recursos naturais voltados principalmente para a subsistência, com fraca articulação com o mercado, baseado em uso intensivo de mão de obra familiar, tecnologias de baixo impacto derivadas de conhecimentos patrimoniais e, normalmente, de base sustentável... Em geral ocupam a região há muito tempo e não têm registro legal da propriedade privada individual da terra, definindo apenas o local de moradia como parcela individual, sendo o restante do território encarado como área de utilização comunitária, com seu uso regulamentado pelo costume e por normas compartilhadas internamente.

Cunha e Almeida (2001, p.192) trazem uma dimensão política ao conceito identificando-o com grupos que conquistam ou estão lutando para conquistar uma identidade pública que inclui algumas das seguintes características: uso de técnicas ambientais de baixo impacto; formas equitativas de organização social; presença de instituições com legitimidade para fazer cumprir suas leis; e, traços culturais seletivamente reafirmados e reelaborados.

Tratam-se então de populações que se caracterizam muito pelo ambiente que as cercam, aliando questões naturais e culturais. Esse conceito pode assim revelar uma necessidade de auto identificação destas populações como espécie de afirmação junto à

3 Disponível em: http://www.brasil.gov.br/governo/2015/04/populacao-indigena-no-brasil-e-de-896-9-mil. Acesso em 23 ago. 2016. 
comunidades externas, mas que não necessariamente representam uma visão interna (CAÑETE e CAÑETE, 2010).

No plano da produção de conhecimento, devemos advertir que é temerário eleger quais conhecimentos são considerados tradicionais. É absolutamente desafiador adentrar nesta instigante questão dos conhecimentos e das comunidades tradicionais. Esse desafio não reside apenas nas terminologias empregadas, mas pelas formas de organização e modos de relacionamento com a natureza. A compreensão de tempo e espaço é apenas uma amostra da complexidade imanente que deve ser empreendida quando analisada. Os conhecimentos desenvolvidos pelas comunidades não se limitam àqueles de natureza prática, associados à sua alimentação e à sua sobrevivência, as comunidades tradicionais apresentam uma predisposição pela busca do conhecimento do entorno em que vivem (LÉVI-STRAUSS, 2006). Do conhecimento dos biomas em que vivem, os membros das comunidades identificam as aplicações e qualidades dos elementos constitutivos destes biomas, que podem servir à sua subsistência e à melhoria das condições de vida de todos.

A OMPI (Organização Mundial de Propriedade Intelectual) entende por "tradicional" aquele conhecimento que apresenta vínculo $\mathrm{cm}$ a comunidade tradicional, responsável por sua preservação e transmissão de geração a geração, que foi criado e preservado em um contexto tradicional, integra a identidade cultural de uma comunidade cultural de uma comunidade, investida no papel de guardiã dos conhecimentos para as futuras gerações, por meio da observância da de normas sociais, disciplinadora do seu uso e transmissão.

É simplista o entendimento de que os conhecimentos tradicionais englobam somente aqueles conhecimentos e técnicas associadas aos recursos da biodiversidade, geralmente conservados por populações tradicionais. A presente tentativa de definição carrega dificuldades intrínsecas para um entendimento correto do conteúdo e alcance do termo, uma vez que nem todos os detentores de conhecimentos tradicionais são classificados como categoria taxativas, além do mais, não são todos os conhecimentos tradicionais que se associam à biodiversidade. Temos, assim, que os conhecimentos tradicionais dos povos indígenas como uma categoria de conhecimentos tradicionais, sendo diferenciado de outros grupos que também os detêm.

De qualquer forma, a origem étnica e arcabouço cultural diferenciado dos detentores dos conhecimentos tradicionais desempenham um papel central na construção de sua definição. Um determinado conhecimento será ou não caracterizado como 
"tradicional" dependendo, dentre outros fatores, de quem o conserva e exerce titularidade. Conhecimentos tradicionais são detidos por grupos marginalizados e culturalmente distintos, os quais, seguindo as tradições de seus antepassados, extraem seus meios de subsistência do meio ambiente natural em que vivem, sem laçar mão de recursos e tecnologias modernas (RODRIGUES JUNIOR, 2010, p. 39).

Assim, cremos que o melhor entendimento acerca dos conhecimentos tradicionais é lecionado pelo Professor J.P. Remédio Marques (2007, p. 352-353), in verbis:

Mas o que deve entender-se por "conhecimentos tradicionais"? podemos defini-lo como o conjunto de saberes - e de fazer (Know how) - que certas populações e indivíduos detêm a respeito do mundo natural e sobrenatural, atinentes à utilização de matérias biológicas vegetais, animais e microbianas, transmitindo oralmente de geração em geração, por isso mesmo inseridos nas tradições culturais e espirituais dessas populações. Cura-se, portanto, de um acervo de "informações" não sistemáticas, vazadas não raro em práticas culturais, individuais ou colectivas, partilhas (e, as mais das vezes, transmitidas intergeracionalmente por certas comunidades humanas (ou por indivíduos que as integram), em territórios mais ou menos determinados, com valor actual ou potencial, associadas às informações genéticas preexistentes em espécies animais, vegetais, microbianas ou em substâncias provenientes do metabolismo desses seres vivos; conhecimentos que são atinentes à localização, identificação, caracterização e utilização das propriedades ou características dessas substâncias - ainda que os "detentores" factícios dos referidos conhecimentos não aprendam a natureza e as características dessas informações genéticas em função dos paradigmas discursivos da ciência moderna. Vale isto dizer que o conceito de conhecimentos tradicionais não abarca não apenas os conhecimentos, mas antes e primacialmente as expressões desses conhecimentos. E o facto de serem conhecimentos "tradicionais" deve-se apenas à forma como são adquiridos e usados.

Entendemos, também, que os conhecimentos tradicionais compreendem inovações, conhecimentos, práticas e técnicas, altamente especializadas, possuidores de premissas que os distinguem dos conhecimentos formais comumente desenvolvidos e utilizados no âmbito da sociedade "moderna".

Denota-se, portanto, uma atividade contemporânea dos membros das comunidades tradicionais, que atualizam os conhecimentos antigos em face das demandas presentes. Deve-se, pois, ter claro que natureza "tradicional" dos conhecimentos de comunidades tradicionais não implica sua antiguidade. O termo "tradicional" confere conteúdo cultural aos conhecimentos, interligando-os à identidade cultural de um determinado grupo humano, ou seja, é tradicional aquele conhecimento gerado e utilizado como parte das tradições de um determinado grupo. Por conseguinte, novos conhecimentos tradicionais são desenvolvidos ininterruptamente pela atividade intelectual dos membros de comunidades locais. Os conhecimentos tradicionais contemporâneos apresentam laços com o passado - 
com o patrimônio cultural acumulado pelo grupo - e com o futuro, porquanto sua sobrevivência depende da conservação de seu patrimônio intelectual.

Todo e qualquer sistema de conhecimento tem raízes culturais, inclusive o sistema científico das sociedades industrializadas. Por isso, não deveria ser uma surpresa à sociedade dominante que outros grupos humanos também tenham desenvolvido sistemas de conhecimentos sofisticados. Portanto, os conhecimentos tradicionais deveriam ser valorizados, respeitados e considerados tão úteis e necessários quanto qualquer outra forma de conhecimento.

Os sistemas tradicionais de conhecimentos, tal como ciência formal, são enraizados em visões específicas de mundo. A ciência formal, que nada mais é que uma das formas de saber, isola o homem do mundo natural e espiritual, enquanto os sistemas tradicionais de conhecimentos valorizam o conhecimento a partir de uma perspectiva holística de mundo. Nesse mesmo sentir é o magistério do Professor J.P. Remédio Marques (2007, p.355):

\begin{abstract}
Daqui resulta que, por via de regra, os conhecimentos tradicionais são holísticos, na medida em que se combinam práticas religiosas, médicas, manifestações artísticas e inovações tecnológicas diuturnamente executadas e adaptadas às necessidades do concreto ecossistema; são, por isso mesmo, complementares de outros conhecimentos, visto que ocorre uma indivisibilidade das vertentes material e espiritual; são auto-sustentados, na medida em que a sua expressão permite proceder à autogestão de todos os recursos biológicos existentes no território habitado pelas comunidades que detêm; são adaptáveis às novas necessidades e realidades postas no ecossistema em que evoluem, são inclusivos, pois são gerados e adaptados, regra geral, pelos utilizadores dos recursos, e não por um corpo especializado de pessoas; são maioritariamente conhecimentos diacrónicos, visto que se baseiam na historicidade dos conhecimentos; e são não sistemáticos e acientíficos, posto que, sendo intuitivos, orientam-se para a resolução de singulares e pontuais problemas, dispensando a formulação de regras e princípios gerais capazes de propiciar a repetibilidade das soluções por parte de outros sujeitos.
\end{abstract}

Outra não menos importante diferença entre o sistema científico formal e o tradicional está no seu formato de representação. O conhecimento científico formal é expresso em formato codificado, ou seja, a sua transmissão é fácil realização, além de ser eminentemente impessoal. O conhecimento ocidental é analítico e valoriza p emprego de instrumentos metodológicos que permitem o distanciamento entre o observador e o objeto pesquisado sem prejudicar o conteúdo analisado. Por sua vez, o conhecimento tradicional é, usualmente, tácito, não estando cristalizado em objetos comerciais (exemplo: uma invenção) e sua transmissão depende de uma relação próxima com a comunidade que o conserva, operacionalizando, em regra, via oral. 
Para muitas comunidades tradicionais, a vida é representada por uma rede de ligações entre o homem, natureza e a espiritualidade: os recursos biológicos e conhecimentos constituíram, respectivamente, uma extensão de sua própria sociedade e uma emanação do mundo espiritual no mundo material.

Embora o nem todo o conhecimento tradicional se associe aos recursos da biodiversidade, geralmente com eles guardam uma relação de forte interdependência. Sem conhecimento um elemento da natureza é apenas um recurso desconhecido, despido de valor. A relação de respeito das comunidades tradicionais para com a natureza reflete seu sábio entendimento de que é ela quem oferece resposta aos seus desafios diários e que, se os recursos naturais não forem aplicados dentro de sua capacidade de regeneração, os meios da sua sobrevivência serão extintos.

O sistema de conhecimento tradicionais mais importante do Sri Lanka tem como raízes a medicina Ayuverda, originária na Índia. Este sistema sofreu mudanças e adaptações no Sri Lanka; receitas foram modificadas e novas plantas locais tomaram o lugar de plantas indianas, alcançando os mesmos propósitos alcançados pelas receitas originais. Este exemplo comprova, empiricamente, que os sistemas de conhecimento tradicionais são dinâmicos e inventivos, afinal substituir plantas estrangeiras por locais, às vezes pertencentes a outros grupos taxonômicos, não é uma tarefa mecânica.

De fato, não é fantasioso associar a função de um recurso da natureza às suas características naturais, por exemplo, uma fatia de cenoura lembra muito um olho; sabiamente, este legume é rico em betacaroteno. A metade de uma noz (gênero Juglans), com seu formato e nervuras, nos remete ao cérebro. A ciência ocidental indica que este fruto contém substâncias fundamentais ao bom funcionamento do cérebro. Portanto, as comunidades tradicionais exercem um papel fundamental na conservação e gestão dos conhecimentos tradicionais de seus recursos biológicos conexos: elas não se veem como proprietários destes recursos da biodiversidade, mas como fieis depositárias de dádivas do criador, em benefício das presentes e futuras gerações. Por essa razão, com frequência esses grupos estabelecem protocolos que reagem sua transmissão, uso e conservação. Assim aquele que recebe um conhecimento tradicional, recebe com ele responsabilidades e não simplesmente direitos de uso. Neste sentido, a parábola dos talentos reflete apropriadamente a perspectiva das comunidades tradicionais de que deter conhecimentos e recursos é deter responsabilidades perante as presente e futuras gerações. 
Diferentemente do julgamento precipitado de alguns de que os conhecimentos tradicionais apenas seriam úteis para o tratamento de problemas de saúde comezinhos, apenas a título de ilustração, vale mencionar que um dos sistemas de conhecimentos médicos do Sri Lanka - o Desiya Chikitsa (RODRIGUES JUNIOR, 2010) - é especializado para tratar uma diversidade de doenças, tais como oculares, fraturas, dermatológicas etc. Contudo, não se pode perder de vista as variadas (pré)compreensões que o instigante tema produz.

A circunstância de o conhecimento tradicional das populações locais e dos povos indígenas - conhecimento, este, que vai associado à utilização in situ dos recursos biológicos, por parte destas "populações indígenas" e das comunidades locais - ser susceptível de merecer a proteção por parte do subsistema dos direitos de propriedade intelectual (direito de autor, direitos conexos e sui generis e direitos de propriedade industrial) não nos deve fazer esquecer a polissemia dos direitos que convoca.

Desde logo, uma primeira leitura poderia acentuar a vertente política do problema ao situar os direitos de propriedade intelectual nas formas de expressão da autonomia étnica e da autodeterminação da eventual nação-Estado que pudesse enquadrar. A segunda leitura enfocaria o mérito dos conhecimentos tradicionais associados à utilização dos recursos biológicos e o incentivo que a outorga de direitos de propriedade intelectual poderia propiciar às comunidades destarte estimuladas (e interessadas) em geri-los e preservá-los de forma equilibrada - por um lado, conhecimentos tradicionais encarados num sentido políticoideológico e, por outros, um sentido jurídico-económico. Uma noção que seja apta a conjugar todas as referidas vertentes do problema valerá por significar que estas comunidades indígenas ou nativas são constituídas pelo acervo de pessoas (constituídas, ou não, em nações), que, desfrutando de uma continuidade histórica das sociedade pré-coloniais ou préinvasoras que ocuparam os mesmo territórios, consideram-se distintas de outros sectores das sociedades hodiernamente prevalecentes e estão determinadas a preservar, desenvolver e transmitir às gerações futuras os territórios ancestrais, bem como a identidade étnica que constitui a base da sua existência como pessoas, no respeito e de harmonia com os seus específicos padrões culturais, instituições legais e sociais.

Esta noção, que temos vindo a utilizar algo acriticamente, revela-se, porém, insuficiente, pois não abrange os conhecimentos tradicionais - conhecimentos estes relativos, por exemplo, a plantas ou ervas medicinais, aromáticas - de populações que jamais foram colonizadas e que não desfrutam do assinalado grau de auto identificação étnico-cultural, e 
que não se regem por tradições e instituições sociais e legais próprias. Basta pensarmos na nossa realidade doméstica: os conhecimentos tradicionais atinentes ao valor medicinal, farmacológico, gastronómico ou aromático de certos recursos biológicos (máxime, recursos biológicos vegetais) são, não raro, partilhados (por vezes, num regime de informação mantida intergeracionalmente secreta) por certas pessoas da mesma família ou da mesma localidade ou conjunto de localidades (MARQUES, 2007, p. 365-367).

\section{DERRUBANDO PÚLPITOS: DESENVOLVIMENTO DE UMA "SOCIOLOGIA DAS AUSÊNCIAS"}

Segundo Boaventura de Souza Santos (2006), vivemos um período de transição entre dois paradigmas de ciência. Um deles, chamada pelo sociólogo português de "ciência moderna", caracterizada, do ponto de vista interno, pela valorização do simples, pela reversibilidade, pelo tempo linear, pela continuidade, pela ênfase sobre a realidade criada, pela valorização da ordem, da certeza e do equilíbrio, pela inclinação ao determinismo, à relação causa-efeito e à separação entre sujeito e objeto. Do ponto de vista externo, este modelo de ciência assume como valores a neutralidade, a indiferença à cultura, o monopólio do conhecimento válido e pretensão de parir o progresso.

Este modelo, a partir do último quartel do século $\mathrm{XX}$, tem enfrentado grandes questionamentos, tem sido cobrado pelas promessas não cumpridas; críticos mais radicais têm ressaltado seu caráter destrutivo e autoritário, apontado a falácia da neutralidade, quando a ciência moderna serve descaradamente a interesses dominantes, acusado a ciência moderna de promover para o paradoxo de que presenciamos um avanço tecnológico mais acelerado que nunca, ao passo estamos estagnados do ponto de vista moral.

Em resposta a esta crise, muitos pensadores tem buscado um novo modelo de ciência que, à falta de uma definição mais clara, é chamada de ciência pós-moderna. Esta, por sua vez, assume como princípios internos a complexidade, em vez do simples; a irreversibilidade em vez da reversibilidade; o uso de tempos não lineares; a descontinuidade preterindo a continuidade; a ênfase não na realidade construída, mas no processo de criação; preferindo a ordem à desordem, a incerteza à certeza e o caos em relação ao equilíbrio como atributos da realidade; a integração sujeito-objeto, ou a intersubjetividade, preterindo a dicotomia sujeito-objeto. Outra característica identificada por Santos (2006) é que, se a 
ciência moderna trabalhava com a redução do humano ao biológico, com a concepção das ciências sociais como um simples epifenômeno das ciências naturais, a ciência pós-moderna faz o contrário: são as ciências naturais que usam de empréstimo categorias antes utilizadas somente nas ciências sociais.

Boaventura de Souza Santos (2006) é um destes estudiosos da transição entre a ciência moderna e pós-moderna e pode-se dizer que sua posição sobre o assunto é bastante ousada. Santos defende não apenas mudanças meramente metodológicas, mas também - e principalmente - uma nova forma de racionalidade, em que se muda radicalmente a forma como a ciência lida com outras formas de conhecimento, como também a forma como a ciência é utilizada como instrumento de poder. Um novo paradigma científico fracassará se não rever as relações de poder Norte-Sul, se não compreender-se como elemento fundamental de hegemonia e contra-hegemonia. É preciso superar, diz o professor, a razão indolente, típica do Ocidente colonizador.

Uma dessas formas de manifestação da razão indolente é a chamada razão metonímica ${ }^{4}$. Por conta dela, temos a predisposição de tomar a parte pelo todo, através da redução da realidade a dicotomias empobrecedoras, em que há sempre uma posição de submissão, tais como secular/religioso; ciência/senso comum; branco/negro; homem/mulher; ocidente/oriente etc. Em todas essas dicotomias, "o todo é menor que a soma das partes", vale dizer, cada uma das partes só pode ser explicada enquanto complemento da outra; todo o conhecimento de um dos pares que não contribuir para manter a dicotomia é simplesmente ignorada.

Como consequência desta mentalidade, ocorre aquilo que o sociólogo português, tomando de empréstimo uma expressão do filósofo Walter Benjamin: "desperdício da experiência", a despeito da riqueza dos acontecimentos do mundo de hoje. Para sobrepor a, esta razão, Santos (2006) apresenta o exercício da sociologia das ausências. Basicamente, esta sociologia consiste em trazer à tona tudo que é ignorado pela razão metonímica, que escolhe somente os elementos que confirmam a dicotomia por ela produzida. De acordo com a sociologia das ausências, à toda lógica de conhecimento e classificação (as "monoculturas") deve ser contraposta uma forma de ecologia. São cinco as principais ausências:

4 Também são manifestações da razão indolente: a) a razão impotente, que imuniza as pessoas de outras responsabilidades, em face da inevitabilidade de certos fenômenos; b) a razão arrogante, que ilude à pessoa com promessas de poder que são nada mais que falácias; c) d) a razão proplética, que sustenta falácias em torno de um futuro linear e inevitável. 
a) as monoculturas do saber, que tendem a sobrevalorizar o conhecimento científico moderno, como única forma legítima de conhecimento, ocultando - ou desconhecendo - as outras formas de conhecimento, como as artes, o senso comum, a religião;

b) as monoculturas do tempo linear, que consideram o tempo linear como única forma de se medir o tempo; formas de marcação temporal que se afastam deste modelo são ignoradas;

c) lógica de classificação social, que privilegia certas categorias sociais em detrimento de outras, o homem é preferível à mulher; o branco preferível ao negro; o ocidental é preferível ao oriental, o urbano é preferível ao rural;

d) lógica da escala dominante estabelece que os fenômenos são somente dignos de consideração quando reproduzem realidades universais; o local é considerado manifestação do "atraso", sendo por isso, substituído como meio de vida pela realidade universalista, que traduz a realidade da "globalização";

e) lógica produtivista, que privilegia somente a prática social que leva à reprodução de capital; o conhecimento que vai além da finalidade da produção, tendo outros valores como a contemplação, a criação de bens simbólicos, é tido como prática ociosa, digna de descrédito.

A essas cinco lógicas, que traduzem bem a razão metonímica, ao estabelecer de forma simétrica, intrinsecamente considerados, um valor e um desvalor, cuja existência deste só se justifica para realçar os valores da sociedade moderna ocidental, Boaventura de Souza Santos contrapõe cinco ecologias, que seria a prospecção e a ressignificação dos valores marginalizados pela razão metonímica. Por estas cinco ecologias (ecologia dos saberes, ecologia dos tempos não lineares, ecologia dos reconhecimentos, ecologia das trans-escalas e ecologia das produtividades), busca-se não uma inversão dos valores, em que o valor desprestigiado alcançaria a supremacia, às custas do desprestígio dos valores outrora dominantes.

O que o autor lusitano defende é que as formas de conhecimento e de estilo de vida dialoguem, em igual respeito e consideração, de modo a que revelem, através da troca de experiências, seus verdadeiros méritos. De acordo com este paradigma, não há conhecimento válido pelo simples fato de pertencer a uma categoria, como acontecia, por exemplo, com o conhecimento científico, que era considerado superior ao senso comum pelo simples fato de 
ser ciência. Ao chamar este diálogo de "ecologia", Santos (2006) faz referência a uma interação sinergética, harmônica, entre estas realidades. Como não há, sem um prévio exame, uma forma de realidade superior à outra, elas não precisam existir somente em função da outra, mas podem existir como realidade autônoma. Pode haver interdependência entre tais realidades, mas não há subordinação de uma à outra.

De outro lado, se a sociologia das ausências pretende um diálogo entre os diversos tipos de experiências, se pretende "expandir o presente" a sociologia das emergências pretende por sua vez "contrair o futuro", ou seja, explorar as diversas formas possíveis de experiências, de modo a amplificar as pistas e sinais de um mundo melhor. A sociologia das emergências tem por finalidade desconstruir a razão proplética, pautada na idéia de progresso linear e na inevitabilidade da História. Segundo esta forma de razão, é um exercício inútil a busca de novas experiências de saberes e práticas, seriam meros "desvios de rota"; a sociologia das emergências parte da premissa de que é muito mais rico trabalhar com uma pluralidade de experiências de mundo, de modo que buscar novas alternativas possíveis.

O autor lusitano cita como exemplo de aplicação das duas propostas de sociologia - tanto das ausências quanto das emergências - a conjugação do conhecimento cientifico com o conhecimento tradicional na exploração da biodiversidade natural. Durante muito tempo, os conhecimentos tradicionais ocupavam um espaço de subordinação ao conhecimento científico-tecnológico, que seria o único capaz de agregar valor; comparado a este, o conhecimento tradicional seria somente um esboço precário, malformado e incompleto como se a ciência também não fosse também incompleta, precária e malformada - do saber cientifico, que se pretendia completo. Daí porque somente a inovação decorrente da ciência e da tecnologia era protegida como propriedade intelectual, enquanto a segunda, até pouco tempo atrás, ou não era reconhecida como propriedade intelectual daquele grupo humano, ou simplesmente não era protegida.

Nos últimos tempos, existe um esforço mundial, vindo principalmente dos países provedores de biodiversidade, no sentido de valorização do conhecimento tradicional, porém não em detrimento do conhecimento científico-tecnológico, mas de forma conjugada, em que um alimenta o outro de informações e experiências, a ponto de produzir conhecimentos novos. Contudo, para que haja esta igual valorização, é necessário que haja também igual consideração das experiências de mundo. Não basta o reconhecimento do conhecimento tradicional como (re)produtor de novos conhecimentos quando se reproduz relações coloniais 
de produção, com a roupagem atual da biotecnologia, naquilo que se chamou de imperialismo verde ou colonialismo verde.

\section{DE ONDE VÊM AS BOAS IDEIAS}

De certa forma, é muito interessante, assim como extremamente producente comparar as conclusões de Boaventura de Souza Santos (2006) não com as de outro pesquisador, mas com a de um escritor, um divulgador da ciência, com bastante repercussão nos meios de comunicação de massa. Steven Johnson escreveu uma obra chamada "De onde vêm as boas ideias" (JOHNSON, 2011), em que procura expor sucintamente quais elementos favorecem a produção de conhecimento científico e tecnológico, chegando à conclusão, após diversos exemplos colhidos da história da ciência, de que uma série de propriedades e padrões compartilhados ocorre reiteradamente em ambientes de excepcionais fertilidade. $\mathrm{O}$ autor identificou sete padrões:

a) possível adjacente - as inovações só encontrarão um ambiente fértil quando houver precondições materiais e intelectuais para tanto. Nenhuma inovação surge somente da atividade especulativa de uma pessoa; é, na verdade, resultado de diversas pequenas modificações, que permitem o surgimento de outras modificações e assim sucessivamente;

b) redes líquidas - as inovações surgem com mais facilidade em ambientes sociais em que as relações interpessoais formam inúmeras conexões, que se fazem e desfazem com enorme fluidez. As redes "líquidas" são um meio termo entre ordens sociais rígidas (“sólidas") e ordens sociais atomizadas e caóticas ("gasosas");

c) intuição lenta - as inovações não ocorrem imediatamente, tão logo venham à mente do inventor; são resultado de um longo processo de depuração, em que são conjugadas com outras idéias, como se estivessem "cozinhando a fogo baixo", até tomarem a forma pela qual se identificam como inovações;

d) serendipidade - o neologismo serendipidade significa o atributo daquilo que surge acidentalmente, como resultado inesperado de uma busca frustrada por outro objeto; 
e) erro - as inovações não ocorrem de modo planejado; diversas vezes, surgem de um erro do inventor/descobridor, que acaba permitindo novas informações, que levem a inovações úteis;

f) exaptação - as inovações não ocorrem somente pela criação de algo novo; podem representar também um uso novo de algo já existente. Na Índia e certas partes da África, por exemplo, comerciantes locais aproveitam pneus para criar sandálias ou solas de sapato;

g) plataformas - as inovações só prosperam quando possuem uma base comum, sobre a qual produzem seus aparatos, que servirão de base para outras inovações. Disto se conclui que todo conhecimento deriva de outros conhecimentos, todos estão interligados.

De modo bastante resumido, as características indicadas por Johnson encontram muito mais identidade com o que chamamos de ciência pós-moderna do que com a chamada "ciência moderna". Contudo, o mais interessante é que o autor busca como exemplo de tais características da inovação não inventos ou descobertas atuais, que se enquadrariam no modelo pós-moderno; os exemplos, desde a invenção da imprensa por Guttenberg a invenção da internet, passando pela construção da Teoria da Seleção Natural de Darwin, pela invenção da máquina de calcular e da televisão, em todas as inovações é possível identificar características que fogem do modelo de ciência da "Razão Indolente". Ou seja, a ciência não é praticada de forma diferente, por meio da mudança de paradigmas: o que mudou foi a forma de compreensão do saber científico, de como a ciência se vê. É inegável - isto o autor não aborda em seu trabalho - que o modelo positivista de ciência servia mais como forma de controle ideológico, comparável a idéia de infalibilidade papal adotada pelas correntes mais tradicionais da Igreja Católica.

Parafraseando Sérgio Buarque de Holanda, ao comparar o modo rigoroso e planejado da construção das capitais da América Espanhola, contrastada com a forma aparentemente caótica adotada pela América Portuguesa (HOLANDA, 2000), a ciência, tanto a moderna quanto a pós-moderna, é mais "semeadora" que "ladrilhadora", é mais caótica que planejada, assim como as demais formas de conhecimento. A diferença é que, se antes, dentro do paradigma da modernidade, buscava-se distinções entre estas formas de conhecimento, o que acabava de certo modo hierarquizando-as, atualmente há cada vez mais estudos, tais quais os aqui citados, que buscam semelhanças entre as formas de saber, o que pode ter um efeito benéfico, no que tange à comunicação entre estes saberes. 


\section{TUTELA DA PROPRIEDADE INTELECTUAL: PROTEGER O QUE DE QUEM?}

Um dos efeitos benéficos desta desconstrução do dito saber cientifico e tecnológico é que se torna obrigatório repensar o seu reflexo jurídico, que é a instituição do regime de propriedade intelectual.

As principais leis de propriedade intelectual partem do princípio de que o inventor ou descobridor é alguém que trabalha individualmente de forma laboriosa, de forma que os frutos colhidos do seu contínuo, planejado e deliberado esforço sejam aproveitados de forma exclusiva, pelo menos por um considerável período de tempo. Com isso, pretendia-se incentivar a produção científica e tecnológica. De outro modo, sem a criação de um regime de propriedade intelectual privada, pouco haveria de avanço científico-tecnológico.

Pode-se levantar duas ligeiras objeções a este modo de pensar. A primeira consiste em que as invenções e descobertas são frutos muito mais de um esforço coletivo desencontrado do que de um esforço individual exclusivo. Um exemplo clássico é a Teoria da Seleção Natural que fora coincidentemente construída, de forma paralela por Darwin e Wallace, sem que um tivesse acesso ao trabalho do outro. Fatos como esse são mais comuns do que se imagina:

Podemos ver as impressões digitais do possível adjacente em um dos mais notáveis padrões de toda a história intelectual, o que os especialistas chamam de "múltiplo": um cientista ou um inventor em algum lugar do mundo tem uma idéia brilhante, mas, quando vai a público e revela seu achado extraordinário, descobre que três outras mentes haviam chegado, de maneira independente, à mesma idéia no ano anterior. As manchas solares foram descobertas simultaneamente em 1611 por quatro cientistas que viviam em quatro países diferentes. A primeira bateria elétrica foi inventada tanto por Dean Von Kleist quanto por Cuneus de Leyden em 1745 e 1746. Joseph Priestley e Carl Wilhem Scheele isolaram o oxigênio entre 1772 e $1774[\ldots]($ JOHNSON, 2011, p. 33).

Os inventos surgem não de gênios individualistas, mas de ambientes sociais propícios ao desenvolvimento do conhecimento. Daí retiramos nossa outra objeção ao modelo de propriedade intelectual, rebatendo a premissa de que o principal motor da inovação é a 
produção de riquezas. Johnson (2011) argumenta que as inovações ocorrem principalmente em ambientes sociais sem finalidades lucrativas. $\mathrm{O}$ autor organizou as principais invenções dentro de um período compreendido entre 1400 a 2000 em quatro quadrantes:

01) inovações criadas por um indivíduo ou um grupo determinado de indivíduos, com finalidade lucrativa (prensa móvel, projeção de Mercator, nylon, revolver, dinamite, arcondicionado, transistor);

02) inovações criadas por grupos difusos na sociedade, com finalidades lucrativas (contabilidade de dupla entrada, máquina de tricô, relógios portáteis, barco a vapor, avião, aço, geladeira, máquina de escrever, telefone, computador pessoal);

03) inovações criadas por um único indivíduo, ou um grupo determinado de indivíduos, sem finalidade lucrativa (descarga de vaso sanitário, paraquedas, rolimãs, piano, diapasão, água gasosa, para-raios, lentes bifocais, nitroglicerina, estetoscópio, world wide web, supercondutores, tomografia computadorizada);

04) inovações criadas por grupos difusos na sociedade, sem finalidade lucrativa (lápis, relógios de pêndulo, telescópio, balão de ar quente, barômetro, eletrocardiograma, computador moderno, contraceptivos orais, incubadora para bebês, penicilina, ponte suspensa, radar, GPS, foguete movido a combustível, internet).

De 1800 até os dias de hoje, segundo o autor, há uma nítida vantagem do quadrante 04 sobre os demais, passando depois a um equilíbrio entre os quadrantes 02 e 03 . O quadrante 01 é o mais vago de todos.

Como indica o cenário acima, o conhecimento é mais fértil em ambientes em que prevalece a colaboração do que ambientes em que predomina a competição, pois nos primeiros as informações correm em fluxo maior, enquanto nos segundos, as informações são represadas.

Apesar disso, a instituição da propriedade intelectual não deixará de existir, pois resguarda interesses políticos bem consolidados. O que se vê, aliás, é um processo de flexibilização do paradigma liberal no qual se criou o atual regime de propriedade intelectual. Neste contexto, opera-se com uma tensão contínua entre o direito de propriedade como incentivo á inovação, com outros valores emergentes, entre eles a proteção das populações tradicionais, historicamente exploradas pelos países provedores de biotecnologia, e a proteção da biodiversidade, que tem sido duramente afetada pelas alterações provocadas pelo desenvolvimento científico-tecnológico. 


\section{A GÊNESE DA TUTELA DO PATRIMÔNIO GENÉTICO COMO DIREITO À PROPRIEDADE INTELECTUAL SUI GENERIS - CONVENÇÃO SOBRE DIVERSIDADE BIOLÓGICA}

Historicamente, o desenvolvimento da biotecnologia era pautado pelo paradigma das relações colônia-metrópole: os países do Norte adquiriam insumos do Sul, a preços ínfimos, coletavam informações sobre os usos do material biológico com as populações locais, que possuem uma relação direta e dependente dos recursos naturais explorados. Com a esperança de adquirir mais dinheiro, a exploração dos insumos naturais alcança proporções predatórias, afetando drasticamente a biodiversidade local. Por outro lado, os produtores de biotecnologia descobriam as fórmulas que geravam o princípio ativo dos recursos biológicos, o reproduzem em forma de remédio a preços bem maiores que a matéria prima coletada e, em casos mais graves, os recursos biológicos locais são substituídos por organismos geneticamente modificados, que são de propriedade das empresas de biotecnologia, não mais das comunidades.

Por todos estes eventos, prospecção biológica encontrou sérias críticas, intensos movimentos de populações tradicionais e populações indígenas, lutando por relações econômica mais equitativas. Um sério obstáculo à proteção dos direitos das populações tradicionais (que aqui incluímos, a falta de categoria mais precisa, as populações indígenas) é que os conhecimentos do quais as empresas de biotecnologia se apoiavam para criar suas fórmulas não eram protegidos pelo regime de propriedade intelectual, pois a eles faltam algumas qualidades típicas de propriedade industrial, mais especificamente a industrialidade (por se tratar de atividade inegavelmente artesanal) e a novidade (por se tratar de atividade exercida há tempos imemoriais, sem registros de criação), afora que os direitos de propriedade intelectual foram criados para serem direitos individuais, e a ideia de direitos difusos e coletivos ainda não era tão desenvolvida como é atualmente. Havia o reconhecimento dos costumes indígenas e tradicionais como patrimônio histórico e cultural, mas que não autorizava partilhar dos resultados e benefícios das pesquisas de prospecção de recursos genéticos. 
Um marco significativo, a despeito de seu teor basicamente programático foi a Convenção de Diversidade Biológica do Rio de Janeiro (CDB), de 05 de junho de 1992. A convenção reconhece em seu preâmbulo "a estreita e tradicional dependência de recursos biológicos de muitas comunidades locais e populações indígenas com estilo de vida tradicionais", e por isso defende que "é desejável repartir equitativamente os benefícios derivados da utilização do conhecimento tradicional, de inovações e de práticas relevantes à conservação da diversidade biológica e à utilização sustentável de seus componentes”.

A CDB protege não apenas os conhecimentos tradicionais associados á biotecnologia, como também a titularidade dos próprios recursos genéticos permite aos Estados compartilhar desse regime sui generis de propriedade, independentemente da existência de conhecimento associado às pesquisas. No art. 15 da Convenção, é reconhecido o “direito soberano dos estados" aos recursos genéticos $\left(\S 1^{\circ}\right.$.), cuja prospecção por empresas de biotecnologia está condicionada ao "consentimento prévio fundamentado" do estado provedor do recurso genético $\left(\S 5^{\circ}\right.$.), assim como autoriza a partilha dos resultados da pesquisa e dos benefícios de sua utilização comercial.

No art. 16, a CDB determina que "o acesso à tecnologia e a sua transferência devem ser facilitados em condições justas e as mais favoráveis" $\left(\S 2^{\circ}\right)$, mesmo que protegidos por propriedade intelectual, que devem ser conciliados com os objetivos da Convenção $\left(\S 5^{\circ}\right)$.

No art. 18, a CDB recomenda a cooperação técnica das empresas de biotecnologia com as partes contratantes, inclusive com uso de "tecnologias indígenas e tradicionais" $\left(\S 4^{\circ}\right)$.

No art. 19, é previsto que o estado provedor de biodiversidade deve ter "acesso prioritário" aos resultados da prospecção, assim como aos benefícios derivados.

Em realidade, apesar de significar uma importante fissura no modelo individualista de propriedade intelectual, a tutela dos conhecimentos tradicionais não teve maiores detalhamentos na CDB. Não se trata de um impedimento imposto pela CDB, mas algo a ser definido pelos próprios estados soberanos, em cada legislação nacional.

\section{PROTEÇÃO DOS CONHECIMENTOS TRADICIONAIS - UM CASO DA LEGISLAÇÃO BRASILEIRA}


O Brasil é um dos países com maior biodiversidade do planeta, principalmente na Região Amazônica. Contudo, somente na virada do Século XX para o XXI é que se instituiu uma legislação para tutelar estes direitos.

O Brasil foi sede da CDB, que ocorreu no Rio de Janeiro, tendo sido assinado em 05 de junho de 1992. Contudo, a convenção foi ratificada somente em 28 de fevereiro de 1994, pelo Decreto Legislativo n. 2/1994 e promulgado pelo Decreto 2.519, de 16 de março de $1998^{5}$.

No plano interno ${ }^{6}$, a questão da tutela dos recursos genéticos e dos conhecimentos tradicionais associados, inicialmente, foi regulada pela Medida Provisória n. 2.186-16, de 23 de agosto de 2001. Nela, o conhecimento tradicional associado é definido como "informação ou prática individual ou coletiva de comunidade indígena ou de comunidade local, com valor real ou potencial, associada ao patrimônio genético". Tanto o patrimônio genético quanto estes conhecimentos são considerados como "patrimônio cultural brasileiro", podendo ser objeto de cadastro (art. $8^{\circ}, \S 2^{\circ}$ da Medida Provisória), com usufruto direto da comunidade detentora do conhecimento. Contemporaneamente, todavia, o presente tema encontra guarida legal na Lei 13.123/15, bem como o Decreto 8.772/16, cuja “evolução" é defendida na mesma medida dos que militam pelo retrocesso em matéria de acesso ao patrimônio genético.

A constituição de propriedade intelectual só será viável se o responsável pela bioprospecção observar os termos da Medida Provisória, de modo a obter o "consentimento prévio fundamentado" e a "repartição equitativa dos recursos", tanto perante a comunidade detentora do conhecimento associado (ainda que o conhecimento seja de uma única pessoa dessa comunidade - art. $9^{\circ}$, parágrafo único) quanto perante o órgão federal competente pela administração destes recursos, o Conselho de Gestão do Patrimônio Genético, vinculado ao Ministério do Meio Ambiente.

Por este instrumento jurídico, pretende-se valorizar o conhecimento tradicional, destacando-o não como "conhecimento imperfeito", pois imperfeito também é o conhecimento científico-tecnológico, mas como patrimônio ao mesmo tempo cultural usando os próprios termos da legislação aplicada - como também é patrimônio em sentido

\footnotetext{
${ }^{5}$ O sistema de incorporação dos tratados, no Brasil, passa pelas seguintes fases: 1) assinatura do tratado, pelo Presidente da República; 2) ratificação do tratado, pelo Congresso Nacional, por meio de Decreto Legislativo, quando o tratado passa a valer fora do território nacional, mas não internamente, o que ocorre com a 3) promulgação, por meio de decreto.

${ }^{6}$ Diante dos escopos do presente trabalho, optamos apenas pela indicação dos instrumentos paradigmas (precedente e atual) reguladores dos conhecimentos tradicionais associados, sem, portanto, fazer uma análise aprofundada condizente com a relevância e complexidade dessa temática.
} 
econômico. Trata-se de um conhecimento holístico, como o definiu João Paulo Remédio Marques (2007), pois ao mesmo tempo que possui caráter prático, pode possuir natureza religiosa, cultural, sem que haja um predomínio de um aspecto sobre o outro.

De acordo com o mesmo autor, os direitos de propriedade imaterial fogem ao modelo clássico de propriedade intelectual, caracterizando forma sui generis de domínio. Se a invenção é protegida em função do trabalho intelectual realizado, os direitos decorrentes da titularidade dos recursos genéticos decorrem não da aplicação industrial destes recursos, mas sim da utilização sustentável dos mesmos, contribuindo para a produção do conhecimento humano como também conservando os recursos naturais de modo racional.

\section{CONSIDERAÇÕES FINAIS}

Uma das críticas que Boaventura de Souza Santos faz ao saber científico moderno é que ele pretende transformar o mundo sem reconhecer que é parte integrante deste mesmo mundo, sujeito ele também às mesmas transformações. O conhecimento científico não se avalia somente pelo resultado das suas técnicas, mas também pelas relações de poder que ele legitima. Vendo deste ângulo, a ciência pode ser tanto fonte de emancipação social, a permitir reconhecimento de grupos sociais antes discriminados, como mecanismo de progresso social, como também pode atuar de forma a legitimar estruturas de poder e iniquidades sociais.

A biotecnologia é um dos campos mais sensíveis a esta discussão, por conjugar tecnologias de ponta com técnicas artesanais; por dispor centros de pesquisa de alcance global, resguardados com vultosos recursos financeiros, com comunidades locais, muitas delas vivendo de subsistência. A legislação emergente de proteção da biodiversidade e dos conhecimentos tradicionais tem sido um exemplo notável de aplicação da sociologia das ausências e emergências proposta por Boaventura de Souza Santos, demonstrando que realidades sociais distintas podem não apenas ser contrapostas de modo que uma implique a negação da outra, em que uma seja explicada exclusivamente em função de ser contrária à outra, mas como experiências complementares, que existem independentemente de antagonismo à outras experiências, igualmente válidas. 
Ao final deste artigo, pode-se perceber, portanto, que o sistema majoritário de propriedade intelectual apresenta profundos déficits relacionados ao modelo de criação dos conhecimentos tradicionais, onde é notória a presença dos recursos da biodiversidade. Faz-se, desta forma, necessário, discutir novas formas de proteção desses conhecimentos, cuja produção é majoritariamente coletivo, decorrente de transmissão geracional, sob pena de leválos a extinção. Adverte-se, porém, em nosso entender, que a saída (tentativa legitima) está dentro do próprio Direito, é ele quem deve se adaptar às complexas exigências dos tempos contemporâneos.

\section{REFERÊNCIAS BIBLIOGRÁFICAS}

ARRUDA, Rinaldo. "Populações Tradicionais" e a proteção de recursos naturais em Unidades de Conservação. In: Ambiente \& Sociedade, ano II, n 5, 1999.

https://doi.org/10.1590/s1414-753x1999000200007

ALBAGLI, Sarita. Seminário Saber Local/ Interesse Global: propriedade intelectual, biodiversidade e conhecimento tradicional na Amazônia. Museu Paraense Emílio Goeldi, Cesupa, Belém, 10 a 12 de setembro de 2003.

ALMEIDA, Alfredo Wagner Berno de (org.). Conhecimento tradicional e biodiversidade: normas vigentes e propostas. 1. $^{\circ}$ vol. Manaus: Programa de Pós-Graduação da Universidade do Amazonas - UEA, 2008.

BRASIL. Decreto 2.519, de 16 de março de 1998, promulga a Convenção Sobre Diversidade Biológica.

BRASIL. Medida Provisória n. 2.186-16, de 23 de agosto de 2001, Regulamenta o inciso II do $\S 1^{\circ}$ e o $\S 4^{\underline{0}}$ do art. 225 da Constituição, os arts. $1^{1}$, $8^{\circ}$, alínea "j", 10, alínea "c", 15 e 16, alíneas 3 e 4 da Convenção sobre Diversidade Biológica, dispõe sobre o acesso ao patrimônio genético, a proteção e o acesso ao conhecimento tradicional associado, a repartição de benefícios e o acesso à tecnologia e transferência de tecnologia para sua conservação e utilização, e dá outras providências.

CAÑETE, V. R.; CAÑETE, T. M. R. Populações Tradicionais Amazônicas: revisando conceitos. In: Anais do V Encontro Nacional da Associação Nacional de Pós-Graduação e Pesquisa em Ambiente e Sociedade. 2010. Florianópolis. Disponível em: 
http://www.anppas.org.br/encontro5/cd/artigos/GT10-29-1009-20100904055930.pdf. Acesso em: 23 ago 2016.

CUNHA, Manuela Carneiro da. "Populações tradicionais e a Convenção da Diversidade Biológica”, Estudos Avançados. 1999. ano 13, vol. 36, São Paulo: USP, 1999.

JOHNSON, Steven. De onde vêm as boas ideias. Trad. Maria Luiza X. de A. Borges. Rio de Janeiro: Zahar, 2011.

LÉVI-STRAUSS, Claude. "A origem dos modos à mesa". Mitológicas. v. 3. São Paulo: Cosac Naify, 2006.

LIMA, André. Quem cala consente? subsídios para a proteção aos conhecimentos tradicionais. São Paulo: Instituto Socioambiental, 2003.

MARQUES, João Paulo Remédio. Biotecnologia(s) e propriedade intelectual (vol. II). Coimbra: Almedina, 2007.

RODRIGUES JUNIOR, Edson Beas. Tutela jurídica dos recurso da biodiversidade dos conhecimentos tradicionais e do folclore: uma abordagem do desenvolvimento sustentável. Rio de Janeiro: Elsevier, 2010.

SANTOS, Boaventura de Souza. A gramática do tempo: para uma nova cultura política. São Paulo: Cortez, 2006. 